\title{
Surveillance of device associated infections and mortality in a major intensive care unit in the Republic of Cyprus
}

\author{
Stelios Iordanou', Nicos Middleton², Elizabeth Papathanassoglou ${ }^{3}$ and Vasilios Raftopoulos ${ }^{2^{*}}$
}

\begin{abstract}
Background: Device-associated health care-associated infections (DA-HAl) pose a threat to patient safety, particularly in the intensive care unit. The aim of this study was to assess the incidence of DA-HAls, mortality and crude excess mortality at a General Hospital's Intensive Care Unit (ICU) in the Republic of Cyprus for 1 year period.

Methods: A prospective cohort, active DA-HAls surveillance study with the use of Health Acquired Infections (HAls) ICU Protocol (v1.01 standard edition) as provided by ECDC/NHSN for the active DA-HAls surveillance study was conducted. The study sample included 198 ICU patients admitted during the research period and hospitalized for over 48 h. The Ventilator-Associated Pneumonia (VAP), Central Line-Associated Bloodstream Infection (CLABSI), and Catheter-Associated Urinary Tract Infection (CAUTI) rates, length of stay (LOS), mortality, and crude excess mortality were calculated.
\end{abstract}

Results: CLABSI was the most frequent DA-HAI with 15.9 incidence rate per 1000 Central Venus Catheter (CVC) days. The VAP rate, was 10.1 per 1000 ventilator days and the CAUTI rate was 2.7 per 1000 urinary catheter days. Device associated infections were found to be significantly associated with the length of ICU stay $(p<0.001)$, the CVC days $(p<0.001)$, ventilator days $(p<0.001)$, and urinary catheter days $(p<0.001)$. The excess mortality was 22. $1 \%$ for those who acquired a DA-HAI (95\% Cl, 2-42.2\%) compared to the patients who remained DA-HAl free. Mortality of patients with VAP infection was 2.3 times higher ( $R R=2.3395 \% \mathrm{Cl}, 1.07-5.05)$ than those patients admitted without a HAI and subsequently did not acquire a DA-HAl. The most frequently isolated pathogen was Staphylococcus epidermidis (13.9\%) and Candida albicans (13.9\%).

Conclusions: Higher DA-HAls rates and device utilization than the international benchmarks were found in this study, calling into question the safety of preventative practices employed in this unit.

Keywords: Healthcare-associated infection, Device associated infection, Intensive care unit, Ventilator associated pneumonia, Central line-associated blood stream infection, Catheter-associated urinary tract infection

\section{Background}

Device-associated health care-associated infections (DA-HAIs) affect the quality of health care in terms of increased morbidity, mortality, and additional cost for patient care provision. DA-HAIs pose a severe threat to patients, despite prevention efforts that have resulted to a significant decrease of infections' incidence [1-5].

\footnotetext{
*Correspondence: vasilios.raftopoulos@cut.ac.cy

${ }^{2}$ Nursing Department, Cyprus University of Technology, 15, Vragadinou Str, 3041 Limassol, Cyprus

Full list of author information is available at the end of the article
}

CLABSIs, VAPs and CAUTIs are the three most common DA-HAIs [6]. The incidence of DA-HAIs in the European Union (EU) countries varies. VAP median rate in 11 major EU countries, reported by ECDC 2014 annual epidemiology report, was 8.4 per 1000 ventilator days (range: $3.9-14.3 / 1000$ device days) with the lowest rates to be reported in Luxemburg (3.2 [2.7-3.9]/1000 device days) and the highest in France (12.8 [8.4-18.3]/ 1000 device days) [7]. The median rate of CLABSIs among ten EU countries was 1.5 per 1000 central vein catheter (CVC) days (0.93-3.27/1000 CVC days) [8] and 
for CAUTI's among 23 EU countries was 1.3 per 1000 urine catheter days (1.2-1.5/1000 CVC days).

The current study is assessing the incidence of DAHAIs, mortality and crude excess mortality of a closed type, General Hospital's ICU in the Republic of Cyprus for 1 year period and reporting the results of the active DA-HAIs surveillance system as a part of a comprehensive prevention program.

\section{Methods}

\section{Setting}

The study was conducted in the ICU of a major public secondary general referral hospital in the Republic of Cyprus with 28.000 yearly hospital admissions. Although this is an adult hospital, pediatric patients can be admitted to the pediatric department but not in the ICU.

The unit is a closed adult ICU, of open plan, case mixed, with eight beds. It serves primarily the south area of the island; however, patients may be admitted from the private and other public hospitals across the Republic of Cyprus. During the day time shift, the staff consists at least of six nurses $(\approx 0.75$ nurse per bed) and five ICU physicians (intentivists) in the morning, whereas during the afternoon and night shift the staff consists of four nurses (one nurse for every two beds) and one physician.

\section{Study design and data collection}

A prospective cohort, active DA-HAIs surveillance study was conducted using standardized survey record form for collecting patients' data, based on the ICU protocol (ECDC-NHSN, HAI-ICU Protocol, v1.01 standard edition) [9] for a period of 12 months (January-December, 2015). The study protocol was approved by the Cyprus Bioethics Committee (EЕKВ/ЕП/2015/37) and reviewed by the Republic of Cyprus Personal Data Commissioner.

\section{Patients}

All the patients admitted to the ICU and hospitalized for more than $48 \mathrm{~h}(n=198)$ were included in the study. They were monitored for DA-HAIs, until their death or discharge from the ICU. Patients' demographics, acute chronic health evaluation (APACHE II) [10], simplified acute physiology score (SAPS II) [11], date and site of DA-HAIs onset, duration of device usage (days), isolated pathogens, antibiogram results, length of patient stay and patient outcome on discharge from ICU were recorded.

The data were collected by experienced ICU nurses and physicians, who had attended a short-term training session regarding the DA-HAIs diagnostic criteria and ECDC-NHSN protocol. Although that infection control committees, have been in operation since 1999, the vast majority of the committee members are not specialized or accredited in infection control.

\section{Sampling and laboratory testing}

All the patients admitted to the ICU were screened to detect multidrug-resistant organisms (MDROs) colonization using an admission surveillance culture protocol (nasal-rectal samples).

Blood samples were collected in case of a suspected blood stream infection. For CLABSIs, the CVC was aseptically removed and the distal $4 \mathrm{~cm}$ of the catheter was separated and cultured. For CAUTIs, urine samples were collected by aseptically aspirating a sample from the urine sample port. Quantitative culture for aerobic bacteria was performed using samples of lower respiratory tract secretions to detect VAP. Lower respiratory tract secretions were collected using tracheal aspiration or/and broncheoalveolar lavage (BAL).

Standard laboratory methods were used to identify microorganisms using automated method Phoenix 100 and Vitek II.

\section{DA-HAls rate calculations}

For estimating DA-HAIs incidence density rates, confirmed VAP events were divided by the number of total ventilator days and multiplied by 1000 . For CLABSI, the confirmed CLABSI events were divided by total CVC days multiplied by 1000 and for CAUTI, the confirmed CAUTI events were divided by total Urine Catheter (UC) days multiplied by 1000 . Device utilization ratios have been calculated by dividing the total number of device-days by the total number of patient-days. Devicedays are the total number of days of exposure to each device (ET, CVC, or UC) for all the patients during the selected time period. Patient-days are the total number of days that patients are in the ICU during the selected time period.

\section{Crude excess mortality}

The mortality of patients with a DA-HAI was compared with the mortality of HAI-free patients (who did not acquire a DA-HAI during their stay in the ICU) by calculating and evaluating crude excess mortality. Crude excess mortality in the ICU was defined as the difference between the crude overall case fatality rate of patients with a DA-HAI and that of patients admitted without a HAI who did not acquire a DA-HAI in the ICU during the same period.

\section{Statistical analysis}

Medians and interquartile ranges (IQR) were used to describe the distribution of continuous variables and frequencies and percentages for categorical variables. Comparisons between the two groups were performed by using the Mann-Whitney $U$ test for continuous variables, and the Fisher exact test or the chi-square test for categorical variables. Relative risk has been calculated 
for comparison of mortality rates for patients with a DA-HAI versus mortality rate for patients admitted without an HAI who did not acquire a DA-HAI. Relative Risks (RRs) were calculated using a bionomial regression with a log link function adjusted by Age. Both unadjusted and adjusted RRs are reported. Descriptive statistics, correlation tests and relative risks were calculated in the IBM-SPSS software, version 21. Moreover, 95\% confidence intervals of the incident rates and excess mortality were calculated in $\mathrm{R}$ version 3.1 .3 [12] using the packages exactci [13] for the incident rates, and PropCIs [14] for the excess mortality.

\section{Results}

During the study period, surveillance data were collected for 198 (73 females [36.9\%] \& 125 males [63.1\%]) patients hospitalized in the ICU for a total of 2269 ICU days.

Median age was 68 years old (IQR, 55-77). The median APACHE II score on admission was 22 (IQR, 16-28), whereas the median SAPS II score was 49 (IQR, 36-65).
Median length of ICU stay was 6 days (IQR, 4-13). The median time interval between admission and identification of the first DA-HAI was 5 days (IQR, 4-10).

One hundred and fifty-one of the 173 patients were admitted without an HAI and did not acquire a DA-HAI during their stay (Table 1).

A total of 43 instances of DA-HAIs were detected in 25 of the 198 patients, indicating an overall infection rate of $12.6 \%$ or an overall incidence of 19 DAHAIs per 1000 ICU-days (95\%[CI:13.7-25.5]). CLABSI (48.8\%, 15.9/1000 device days) was the most commonly encountered type of infection accounting for $48.8 \%$ of all the DA-HAIs, followed by VAP $(37.2 \%$, $10.1 / 1000$ device days) and CAUTI (14\%, 2.7/1000 device days). The proportion of patients exposed to mechanical ventilation was $70 \%$, those exposed to central catheters were $58 \%$ and those to urinary catheters 99\% (device utilization $0.70,0.58$ and 0.99 for mechanical ventilation, central catheters and urinary catheters respectively) (Table 2 ).

Table 1 Baseline characteristics across patients who acquired a DA-HAI

\begin{tabular}{|c|c|c|c|c|c|c|}
\hline \multirow[t]{2}{*}{ Characteristic } & \multicolumn{2}{|c|}{ Patients without infection $(n=173)$} & \multicolumn{2}{|c|}{ Patients with infection $(v=25)$} & \multirow[b]{2}{*}{$p$-valuet } & \multirow[t]{2}{*}{ All patients $(n=198)$} \\
\hline & $\overline{N(\%)}$ & Median (IQR) & $\overline{N(\%)}$ & Median (IQR) & & \\
\hline \multicolumn{7}{|l|}{ Gender } \\
\hline Female & $67(38.7)$ & & $6(24.0)$ & & 0.187 & $73(36.9)$ \\
\hline Male & $106(61.3)$ & & $19(76.0)$ & & & $125(63.1)$ \\
\hline Age in years & & $68(56-79)$ & & $67(49-70)$ & 0.081 & $68(55-77)$ \\
\hline Days of ICU stay & & $6(4-9)$ & & $31(22-40)$ & $<0.001$ & $6(4-13)$ \\
\hline Apache II score & & $22(16-28)$ & & $25(18-29)$ & 0.294 & $16(22-28)$ \\
\hline SAPS $\|$ & & $49(36-65)$ & & $48(38-66)$ & 0.625 & $49(36-65)$ \\
\hline \multicolumn{7}{|l|}{ Type of admision } \\
\hline medical & $124(71.7)$ & & $17(68.0)$ & & 0.701 & $141(71.2)$ \\
\hline schedule surgical & $3(1.7)$ & & $0(0.0)$ & & & $3(1.5)$ \\
\hline Unschedule surgical & $46(26.6)$ & & $8(32.0)$ & & & $54(27.3)$ \\
\hline \multicolumn{7}{|l|}{ Origin of patient } \\
\hline Community & $60(34.7)$ & & $3(12.0)$ & & 0.004 & $63(31.8)$ \\
\hline LTCF $^{a}$ & $2(1.2)$ & & $2(8.0)$ & & & $4(2)$ \\
\hline other ICU & $33(19.1)$ & & $10(40.0)$ & & & $43(21.7)$ \\
\hline Ward this or other hospital & $78(45.1)$ & & $10(40.0)$ & & & $88(44.4)$ \\
\hline Trauma & $22(12.7)$ & & $5(20.0)$ & & 0.349 & $27(13.6)$ \\
\hline Impaired immunity & $31(17.9)$ & & $7(28.0)$ & & 0.276 & $38(19.2)$ \\
\hline Antimicrobial treatment & $156(90.2)$ & & $24(96.0)$ & & 0.48 & $180(90.9)$ \\
\hline Acute Coronary care & $41(23.7)$ & & $8(32.0)$ & & 0.456 & $49(24.7)$ \\
\hline Central Vascular Catheter DAYS & & $6(4-10)$ & & $15.5(9-33)$ & $<0.001$ & $7(4-12)$ \\
\hline Mechanical Ventilation DAYS & & $5(2-8)$ & & $23(10-39)$ & $<0.001$ & $6(3-10)$ \\
\hline Urinary catheter DAYS & & $6(4-9)$ & & $31(22-40)$ & $<0.001$ & $6.5(4-13)$ \\
\hline
\end{tabular}

†Chi-square test for type of admission and origin of patients. Fisher's exact test for the rest of the categorical variables. Man-Whitney $U$ test for the scale variables (e.g. Age. Days in ICU. etc.)

a Long Term Care Facility 
Table 2 Type and incidence of DA-HAls

\begin{tabular}{llllllll}
\hline & Device-days & Device use & No. of infections & \% of infections & Incidence per 100 patients & Incidence per 1000 device-days & Exact 95 Cl \\
\hline VAP & 1584 & 0.70 & 16 & 37.2 & 8.08 & 10.10 & 10.4 \\
CLABSI & 1318 & 0.58 & 21 & 48.8 & 10.61 & 15.93 & 2.8 \\
CAUTI & 2259 & 0.99 & 6 & 14.0 & 3.03 & 2.66 & 9.9 \\
\hline
\end{tabular}

CAUTI catheter-associated urinary tract infection, CLABSI central catheter-associated bloodstream infection, VAP ventilator-associated pneumonia

Patients who did not acquire a DA-HAI, had a median ICU stay of 6 days (IQR, 4-9), while patients who acquired at least one DA-HAI had a median ICU stay of 31 days (IQR, 22-40). The crude ICU mortality was $40 \%$ $(10 / 25)$ for the patients who acquired a DA-HAI and $17.9 \%(31 / 173)$ for those without a DA-HAI, yielding an overall excess mortality of $22.1 \%$ (95\% CI, 4.2-42.2\%). The multivariate binomial regression model adjusted for age, showed that the mortality rate of patients who acquaired a DAI, was 2.65 times higher ( $R R=2.6595 \%$ C.I.(1.48-4.72) than that of the patients who did not acquire a DAI during their stay.

The crude ICU mortality rate (Table 3 ) was $16.6 \%$ for patients admitted without an HAI who did not acquire a DA-HAI in the ICU. The crude ICU mortality rate for patients with VAP $(38.5 \%)$ is 2.3 times higher $(\mathrm{RR}=2.33$ 95\% C.I.(1.07-5.05) than the crude mortality rate for patients without HAI on admission, who did not acquire a DA-HAI in the ICU (16.7\%), yielding an overall crude excess mortality rate of $21.9 \%$. When adjusting for the age of the patient, the RR of mortality of VAP patients over the nonHAI/nonDAI, is increased to 3.62 (95\% C.I.(1.64-7.98).

\section{Microorganisms' profile and antimicrobial resistance}

The most frequently isolated pathogens, were Staphylococcus epidermidis (13.9\%), Candida albicans (13.9\%), Pseudomonas Aeruginosa (11.6\%), followed by Stenotrophomonas Maltophilia (7\%), Escherichia coli (7\%) and Acinetobacter Baumannii (7\%). Staphylococcus aureus was detected in 2 DAIs (4.6\%).

Table 3 Mortality rates for DA-HAls

\begin{tabular}{|c|c|c|c|c|c|c|c|}
\hline & & Mor & tality & & Relati & ive Risk & \\
\hline & Total patients & Cruc & & Crude excess & & $95 \mathrm{Cl}$ & \\
\hline & & N & & & RR & Lower & Upper \\
\hline None $^{a}$ & 151 & 25 & 16.6 & & & & \\
\hline VAP & 13 & 5 & 38.5 & 21.8 & 2.33 & 1.07 & 5.05 \\
\hline CLABSI & 15 & 5 & 33.3 & 16.7 & 2.01 & 0.90 & 4.48 \\
\hline CAUTI & 6 & 2 & 33.3 & 16.7 & 2.01 & 0.61 & 6.58 \\
\hline
\end{tabular}

a Patients admitted with no HAl and acquired no HAI no DA-HAl. Table presents Risk Ratios (RRs) unadjusted of any demographic characteristics. The multivariate model adjusting for Age revieled the following RRs: VAP:RR $=3.6295 \%$ C.I.(1.64-7.98), CLABSI:RR = 2.32 95\% C.I.(1.04-5.15), CAUTI:RR = 2.37 $95 \%$ C.I. (0.73-7.74)
Pseudomonas Aeruginosa $(n=4 / 25 \%)$, Candida albicans $(n=4 / 25 \%)$, and Acinetobacter Baumannii $(n=2 /$ $12.5 \%)$ were most prevalent in the 16 cases of VAP. Staphylococcus epidermidis $(n=6 / 25.6 \%)$ was most prevalent in the 21 cases of CLABSI, followed by Stenotrophomonas Maltophilia, Staphylococcus Haemolyticus, other coagulase-negative staphylococci and Escherichia coli with 2 cases each (9.5\%).

Candida albicans ( $n=2 / 33.3 \%)$ was most prevalent in CAUTI infections. Candida tropicalis, Enterobacter Gergoviae, Escherichia coli and Pseudomonas Aeruginosa microbes appeared once (Table 4).

\section{Resistance}

The two cases of Staphylococcus aureus were MRSA (oxacillin resistant) but sensitive to Glycopeptides (vancomycin, teicoplanin). All three cases of Acinetobacter Baumannii $(n=3 / 100 \%)$ were resistant to carbapenems

Table 4 Pathogen prevalence out of the 43 DAls

\begin{tabular}{|c|c|c|c|}
\hline ECDC CODE & PATHOGEN & & NUMBER \\
\hline STAEPI & Staphylococcus epidermidis & 13.95 & 6 \\
\hline CANALB & Candida albicans & 13.95 & 6 \\
\hline PSAER & Pseudomonas aeruginosa & 11.63 & 5 \\
\hline STEMAL & Stenotrophomonas maltophilia & 6.98 & 3 \\
\hline ESCCOL & Escherichia coli & 6.98 & 3 \\
\hline ACIBAU & Acinetobacter baumannii & 6.98 & 3 \\
\hline ENCFAE & Enterococcus faecalis & 4.65 & 2 \\
\hline STAHAE & Staphylococcus haemolyticus & 4.65 & 2 \\
\hline STAOTH & Other coagulase-negative staphylococci & 4.65 & 2 \\
\hline SERMAR & Serratia marcescens & 4.65 & 2 \\
\hline CANKRU & Candida krusei & 2.33 & 1 \\
\hline STAAUR & Staphylococcus aureus & 2.33 & 1 \\
\hline CANTRO & Candida tropicalis & 2.33 & 1 \\
\hline ENBCLO & Enterobacter cloacae & 2.33 & 1 \\
\hline STANSP & Staphylococcus spp.. not specified & 2.33 & 1 \\
\hline CANPAR & Candida parapsilosis & 2.33 & 1 \\
\hline ENBGER & Enterobacter gergoviae & 2.33 & 1 \\
\hline SERLIQ & Serratia liquefaciens & 2.33 & 1 \\
\hline KLEOTH & $\begin{array}{l}\text { Klebsiella species. (Non oxytoca. } \\
\text { Non pneumoniae) }\end{array}$ & 2.33 & 1 \\
\hline Total & & 100.00 & 43 \\
\hline
\end{tabular}


(imipenem, meropenem, doripenem - not ertapenem) and collistin. Out of the 5 cases of Pseudomonas Aeruginosa, 5 (100\%) were Ceftazidim sensitive, 3 (60\%) sensitive to Piperacillin or Ticarcillin with or without enzyme inhibitor and $3(60 \%)$ sensitive to carbapenems (imipenem, meropenem, doripenem - not ertapenem). Two cases (40\%) were resistant to Piperacillin or Ticarcillin and to carbapenems one case (20\%) was resistant to collistin.

There were eight cases of Enterobacteriaceae with pathogens which were found to be Serratia Marcescens (2) Klebsiella species. (non oxytoca, non pneumoniae) (1), Enterobacter gergoviae (1), Escherichia coli (2) and Enterobacter cloacae (2). These cases were sensitive to carbapenems (6/75\%), third generation cephalosporins (cefotaxime, cetriaxone, ceftazidime) (5/62.5\%) and amoxicillin/clavulanate (3/37.5\%). Enterobacteriaceae resistance was found on carbapenems (25\%), third generation cephalosporins (3/37.5\%) and amikacin (5/62.5\%). Extended beta-lactamase producer, was found on 3 (37.5\%) of the Enterobacteriaceae.

\section{Discussion}

This study reports the results of the first active DA-HAIs surveillance study that has been conducted in an ICU of the southern part of the Republic of Cyprus. The overall DA-HAIs rate is $12.62 \%$ or 19 DA-HAIs per 1000 ICU days. Even though our rates are significantly lower than the rates reported in other studies [15-20], our findings suggest that such rates have an impact on the length of stay (LOS) and mortality rate. Patient with DA-HAIs had a median LOS longer than patients without DAI-HAIs. The overall excess mortality of the patients who acquired DA-HAI (22.1\%) was lower than the previous Cypriot report [20] (33.2\%) and twice higher than that reported at the International Nosocomial Infection Control Consortium in Lebanon (INICC-2012) (9.8\%) [21].

Utilization rates were found to be 70,58 and $99.6 \%$ for mechanical ventilation (MV), central catheters (CVC) and urinary catheters (UC) respectively. The findings of the study for MV and CVC were significantly lower than INICC [22] 2009-2015 (74, 104 and 82\% respectively) and Greek report for 2013 [15] (95\%, 94\% respectively), but all were much higher than INICC 2004-2009 [23], INICC 2007-2012 [24] and other studies [25]. Utilization rates and severity scores must be examined together in order to reflect the severity index of the patients that were admitted to the ICU, since the increased device utilization may be a result of disease severity.

In our study, the median for APACHE II and SAPS II scores for patients with and without DA-HAI were found to be 22 vs 25 and 49 vs 48 respectively. There was not any significant correlation between the two scoring systems or the DA-HAI positive and negative groups. However, predicted mortality rate (PMR) for
APACHE II [26] (22 to 25 score) was 40-55\% and for SAPS II [11] (48-49 score) 50\%. PMR calculations using APACHE II score, indicates that patients' health condition severity in our study is higher than reported for New York (2004-2007) [27], higher than the Greek report observations for 2013 (16 [score]/15\% [PMR]) [15] and similar to Haq et al. 2014 [28]. Comparisons between the similar reported severity scores studies [15, 27] and their device utilization rate showed large deviation. This probably means that severity scores cannot estimate or be a sole drive factor for device utilization use. Overall extended device utilization rates in our findings require further investigation.

The most commonly encountered infection was CLABSI (48.8\%) followed by VAP (37.2\%) and CAUTI (14\%). The hierarchical distribution of DA-HAIs, CLABSI and VAP rates appears to be similar $[15,20$, 29-31] or different [22, 32] with the current study pattern, but in general ICU CAUTI rates are found to be fewer in most reports [15, 20, 22, 29, 31, 33].

Incidence density rates for VAP, CLABSI and CAUTI were $10.1,15.9$ and 2.7 per 1000 device-days respectively. In comparison with the findings of the previous Cypriot report [20] higher VAP density rates were found (10.1 vs 6.4). Rates were the same for CAUTI (2.66 vs 2.8) but slightly lower rates for CLABSI (15.9 vs 17.9) were observed [15] for VAP, slightly lower for CAUTI (10.1 vs 20, 2.66 vs 4.3 respectively) and higher for CLABSI (15.9 vs 11.8). Our findings showed lower rates compared to the INICC Malaysia report 2016 [22] for VAP (10.1 vs 21) and CAUTI (2.66 vs 5) and higher CLABSI (15.9 vs 9.4). Overall, DA-HAIs rates results are much higher than the participating NHSN report [34] ICUs: for VAP, 10.1 versus 4; for CLABSI, 15.9 versus 3 and lower for CAUTI, 2.66 versus 3.2 infections per 1000 device-days. These findings lead us to the conclusion that a comprehensive program for reducing VAP and CLABSI is a necessity in this ICU.

A crude ICU mortality rate of $40 \%$ for the patients who acquired DA-HAI and $17.9 \%$ for patients who did not, was observed. These findings are higher than INICC for Cuba [35] and Greece [15] but similar to the previous Cypriot [20] report (33, 31.2 and $42.6 \%$ respectively). The higher rates of our study may reflect a higher severity of underlying disease, since the APACHE II and SAPS II scores are higher than some of the comparison studies.

Crude excess mortality for VAP (21.9\%) was higher than CLABSI (16.7\%) and CAUTI (16.7\%), and higher than data reported by the INICC 2004-2009 [23] (15.2\%), INICC 2009-2015 [22] (14.8\%), an Egyptian study [36] (12.9\%) and Greece (13.0\%). CLABSI crude excess mortality (16.7\%) was found to be three times lower than the Egyptian study report (45.7\%), similar to INICC 2004-2009 report (14.7\%) [23] and lower than 
the Greek report (20.6\%) [15]. CAUTI excess mortality was found to be similar to CLABSI (16.7\%) in the results of the current study, lower than Greek report [15] (18.7\%) and significantly lower than INICC 2009-2015 [22] (32.2\%). Overall VAP crude excess mortality is shown as higher and CLABSI and CAUTI similar to or lower than the international benchmarks.

Compared to EU ICU data, the proportion of Pseudomonas aeruginosa isolation (11.63\%) was lower than most of the EU countries, similar to Germany and twice higher than United Kingdom, Candida albicans (13.95\%) lower than Austria and higher than the other 12 and Stenotrophomonas maltophilia (6.98\%) lower then Luxemburg and higher than the rest. In general all the proportions of isolation pathogens found in this study were higher than the majority of the reported pathogens proportion in ICUs across EU [7]. Unexpectedly high was the proportion of Staphylococcus epidermidis isolation (13.9\%). This finding may reflect problems in sample collection procedure or diagnosis.

These results will be presented to the staff, in order to create the sense of urgency followed by an intervention that includes the implementation of a comprehensive care-bundle approach program for infection surveillance, prevention and control in order to improve their compliance with standard precautions and devices maintenance in the current ICU.

\section{Limitations}

The current study has certain limitations. The study was conducted in one of the only two closed type, adult ICUs in Cyprus. These results cannot be generalized to other public or private hospital settings. DA-HAIs cost estimation was one of the study limitations due to the lack of financial reports.

Despite the study's limitations, it can provide clinicians with valuable data with regard to incidence rates and prevalence of DA-HAIs as data for the Republic of Cyprus cannot be found easily in the published literature due to the lack of a Cypriot infection surveillance system.

\section{Conclusions}

In this study, the high incidence rates of DA-HAIs prevalence, device utilization and the antimicrobial resistance pattern, were found to emphasize the need to implement a comprehensive care-bundle approach program. A national active infection surveillance system can be set up to improve current infection control, data collection practices as well as changes in device usage and their maintenance.

\section{Abbreviations}

CAUTI: Catheter-associated urinary tract infection; CLABSI: Central lineassociated blood stream infection; CVC: Central venus catheter; DAHAl: Device-associated health care-associated infections; ICU: Intensive care unit; VAP: Ventilator associated pneumonia

\section{Acknowledgments}

We would like to thank all the individuals who participated in this study.

Funding

None.

Availability of data and materials

All data generated or analysed during this study are included in this published article. The data will be freely available to any scientist wishing to use them for non-commercial purposes. The data can be requested from the first author of the manuscript.

\section{Authors' contributions}

VR and SI conceived of, designed, coordinated the study, reviewed the statistical analysis, prepared and revised the manuscript. SI collected the data and performed the statistical analysis. VR was the main PhD advisor of the first author (SI). NM and EP were members of the PhD advisory committee and were involved in the overall supervision of the study and the revision of the manuscript. All authors have read and approved the final version of the manuscript.

\section{Ethics approval and consent to participate}

The study protocol was approved by the Cyprus Bioethics Committee (EEKB/ ЕП/2015/37) and reviewed by the Republic of Cyprus Personal Data Commissioner. The Special Research Committee in the Ministry of Health has given its permission to conduct the study and collect patients' data according to the principles of the Declaration of Helsinki. There is no need for patients' or their legal tutors' consent before the enrolment in the surveillance study, since the data were anonymously collected.

Consent for publication

Not applicable.

\section{Competing interests}

The authors declare that they have no competing interest.

\section{Publisher's Note}

Springer Nature remains neutral with regard to jurisdictional claims in published maps and institutional affiliations.

\section{Author details}

${ }^{1}$ Nursing Department, General Hospital of Limassol, Cyprus University of Technology, Limassol, Cyprus. ${ }^{2}$ Nursing Department, Cyprus University of Technology, 15, Vragadinou Str, 3041 Limassol, Cyprus. ${ }^{3}$ Faculty of Nursing, University of Alberta, Edmonton, Alberta, Canada.

Received: 24 March 2017 Accepted: 23 August 2017

Published online: 06 September 2017

References

1. Fagan RP, Edwards JR, Park BJ, Fridkin SK, Magill SS. Incidence trends in pathogen-specific central line-associated bloodstream infections in US intensive care units, 1990-2010. Infect Control Hosp Epidemiol. 2013 [cited 2016 Aug 4];34:893-899. Available from: http://www.ncbi.nlm.nih.gov/ pubmed/23917902.

2. Rosenthal VD, Guzman S, Migone O, Crnich CJ. The attributable cost, length of hospital stay, and mortality of central line-associated bloodstream infection in intensive care departments in Argentina: A prospective, matched analysis. Am. J. Infect. Control. Bernal Medical Center, Colegiales Medical Center, Department of Infectious Diseases, and Hospital Epidemiology, Buenos Aires, Argentina.; 2003;31:475-80.

3. Dima S, Kritsotakis El, Roumbelaki M, Metalidis S, Karabinis A, Maguina N, et al. Device-associated nosocomial infection rates in intensive care units in Greece. Infect. Control Hosp Epidemiol. 2007;28:602-5. 
4. Klevens RM, Edwards JR, Richards Jr CL, Horan TC, Gaynes RP, Pollock DA, et al. Estimating health care-associated infections and deaths in U.S. hospitals, 2002. Public Heal. reports (Washington, D.C. 1974). Division of Healthcare Quality Promotion, National Center for Infectious Diseases, Centers for Disease Control and Prevention, 1600 Clifton Rd., MS A-24, Atlanta, GA 30333, USA.; 2007;122:160-6.

5. Centers for Disease Control and Prevention (CDC). Vital signs: central lineassociated blood stream infections-United States, 2001, 2008, and 2009. MMWR. Morb. Mortal. Wkly. Rep. [Internet]. 2011 [cited 2016 Aug 4];60:243-8. Available from: http://www.ncbi.nlm.nih.gov/pubmed/21368740.

6. Vincent JL, Bihari DJ, Suter PM, Bruining HA, White J, Nicolas-Chanoin MH, et al. The prevalence of nosocomial infection in intensive care units in Europe. Results of the European Prevalence of Infection in Intensive Care (EPIC) Study. EPIC International Advisory Committee. JAMA. [cited 2016 Nov 14];274:639-44. Available from: http://www.ncbi.nlm.nih. gov/pubmed/7637145.

7. European Centre for Disease Prevention and Control. Annual epidemiological report 2014. Antimicrobial resistance and healthcareassociated infections [Internet]. 2014. Available from: http://ecdc.europa.eu/ en/publications/publications/antimicrobial-resistance-annualepidemiological-report.pdf.

8. Hansen S, Schwab F, Behnke M, Carsauw H, Heczko P, Klavs I, et al. National influences on catheter-associated bloodstream infection rates: practices among national surveillance networks participating in the European HELICS project. J Hosp Infect. 2009 [cited 2016 Nov 16];71:66-73. Available from: www.elsevierhealth.com/journals/jhin.

9. ECDC-NHSN. Infections in Intensive Care Units HAI-ICU protocol [Internet]. Eur. Surveill. Heal. Infect. Intensive Care Units- ECDC HAllCU Protoc. 2010. p. 1-68. Available from: http://ecdc.europa.eu/en/aboutus/calls/ ProcurementRelatedDocuments/5_ECDC_HAllCU_protocol_v1_1.pdf.

10. Knaus WA, Draper EA, Wagner DP, Zimmerman JE. APACHE II: a severity of disease classification system. [Internet]. Crit. Care Med. 1985 [cited 2016 Oct 23]. p. 818-29. Available from: http://www.ncbi.nlm.nih. gov/pubmed/3928249.

11. Le Gall J-R, Lemeshow S, Saulnier F. Simplified acute physiology score ( SAPS II ) based on a European / north American multicenter study. JAMA. 1993 [cited 2016 Oct 23];270:2957-2963. Available from: http://www.ncbi. nlm.nih.gov/pubmed/8254858.

12. R Development Core Team. R: A language and environment for statistical computing. R Foundation for Statistical Computing, Vienna. URL http://www.R-project.org/. R Found Stat Comput. Vienna. 2015;2015.

13. Fay MP. Two-sided exact tests and matching confidence intervals for discrete data. R J. 2010;2:53-8. Available from: https://journal.r-project.org/ archive/2010-1/RJournal_2010-1_Fay.pdf.

14. Ralph Scherer. Various confidence interval methods for proportions [Internet]. 2014. Available from: https://github.com/shearer/PropCls.

15. Apostolopoulou E, Raftopoulos V, Filntisis G, Kithreotis P, Stefanidis E, Galanis $P$, et al. Surveillance of device-associated infection rates and mortality in 3 greek intensive care units. Am J Crit Care. Nursing Department, National and Kapodistrian University of Athens, Greece.; 2013 [cited 2016 Jan 4];22:e12-e20. Available from: http://www.ncbi.nIm.nih.gov/ pubmed/23635940.

16. Hidron Al, Edwards JR, Patel J, Horan TC, Sievert DM, Pollock DA, et al. NHSN annual update:antimicrobial-resistant pathogens associated with healthcare-associated infections: annual summary of data reported to the National Healthcare Safety Network at the Centers for Disease Control and Prevention, 2006-2007. Infect Control Hosp Epidemiol. 2008;29:996-1011. Available from: https://www.ncbi.nlm.nih.gov/pubmed/18947320.

17. Inan D, Saba R, Yalcin AN, Yilmaz M, Ongut G, Ramazanoglu A, et al. Deviceassociated nosocomial infection rates in Turkish medical-surgical intensive care units. Infect Control Hosp Epidemiol. 2006;27:343-8. Available from: https://www.ncbi.nlm.nih.gov/pubmed/16622810.

18. Kübler A, Duszynska W, Rosenthal VD, Fleischer M, Kaiser T, Szewczyk E, et al. Device-associated infection rates and extra length of stay in an intensive care unit of a university hospital in Wroclaw, Poland: international Nosocomial infection control Consortium's (INICC) findings. J Crit Care. 2012 [cited 2016 Nov 7];27:105.e5-105.e10. Available from: http://linkinghub. elsevier.com/retrieve/pii/S0883944111002206.

19. Salomao R, Rosenthal VD, Grimberg G, Nouer S, Blecher S, Buchner-Ferreira $S$, et al. Device-associated infection rates in intensive care units of Brazilian hospitals: findings of the international Nosocomial infection control consortium. Rev Panam Salud Publica. 2008 [cited 2016 Nov 7];24:195-202. Available from: http://www.ncbi.n/m.nih.gov/pubmed/19115547.

20. Gikas A, Roumbelaki ÁM, Bagatzouni-Pieridou D, Alexandrou M, Zinieri $\checkmark$, Kritsotakis El. Device-associated infections in the intensive care units of Cyprus: results of the first national incidence study. Infection. 2010; 38:165-71.

21. Kanj S, Kanafani Z, Sidani N, Alamuddin L, Zahreddine N, Rosenthal V. International nosocomial infection control consortium findings of deviceassociated infections rate in an intensive care unit of a Lebanese university hospital. J Glob Infect Dis. 2012;4:15. Available from: http://www.jgid.org/ text.asp?2012/4/1/15/93755.

22. Rosenthal VD. Device-associated infection and mortality rates, bacterial resistance, and length of stay in hospitals of Malaysia: international Nosocomial infection. Can J Infect Control. 2016;31:107-12.

23. Rosenthal VD, Bijie H, Maki DG, Mehta Y, Apisarnthanarak A, Medeiros EA, et al. International Nosocomial infection control consortium (INICC) report, data summary of 36 countries, for 2004-2009. Am J Infect Control. 2012 [cited 2016 Nov 7];40:396-407. Available from: http://linkinghub.elsevier. com/retrieve/pii/S019665531100842X.

24. Rosenthal VD, Maki DG, Mehta Y, Leblebicioglu H, Memish ZA, Al-Mousa HH, et al. International Nosocomial infection control Consortiu (INICC) report, data summary of 43 countries for 2007-2012. Device-associated module. Am J Infect Control. 2014 [cited 2016 Nov 7];42:942-956. Available from: http:// linkinghub.elsevier.com/retrieve/pii/S0196655314008566.

25. Rosenthal VD, Maki DG, Mehta A, Álvarez-Moreno C, Leblebicioglu H, Higuera F, et al. International Nosocomial infection control consortium report, data summary for 2002-2007, issued January 2008. Am J Infect Control. 2008 [cited 2016 Nov 7];36:627-637. Available from: http:// linkinghub.elsevier.com/retrieve/pii/S0196655308001661.

26. Knaus WA, Draper EA, Wagner DP, Zimmerman JE. APACHE II: a severity of disease classification system. Crit Care Med. 1985;13:818-29.

27. Venkatram S, Rachmale S, Kanna B. Study of device use adjusted rates in health care-associated infections after implementation of "bundles" in a closed-model medical intensive care unit. J. Crit. Care. 2010;25:174.e11-174. e18. Available from: http://www.ncbi.nlm.nih.gov/pubmed/19682846.

28. Haq A, Patil S, Parcells AL, Chamberlain RS. The Simplified Acute Physiology Score III Is Superior to the Simplified Acute Physiology Score II and Acute Physiology and Chronic Health Evaluation II in Predicting Surgical and ICU Mortality in the \&quot;Oldest Old\&quot. Curr. Gerontol. Geriatr. Res. 2014 [cited 2016 Nov 8];2014:934852. Available from: http://www.ncbi.nlm.nih. gov/pubmed/24696680.

29. Rosenthal VD, Guzman S, Orellano PW. Nosocomial infections in medicalsurgical intensive care units in Argentina: attributable mortality and length of stay. Am J Infect Control. 2003;31:291-5.

30. Gould C V, Umscheid CA, Agarwal RK, Kuntz G, Pegues DA. Guideline for prevention of catheter-associated urinary tract infections 2009. Infect Control Hosp Epidemiol. 2010 [cited 2016 Jan 4];31:319-326. Available from: http://www.ncbi.nlm.nih.gov/pubmed/20156062.

31. Umscheid CA, Mitchell MD, Doshi JA, Agarwal R, Williams K, Brennan PJ. Estimating the proportion of healthcare-associated infections that are reasonably preventable and the related mortality and costs. Infect. Control Hosp. Epidemiol. Center for Evidence-Based Practice, University of Pennsylvania, Philadelphia, Pennsylvania 19104, USA. craig.umscheid@uphs. upenn.edu; 2011;32:101-14.

32. Rosenthal VD, Maki DG, Salomao R, Moreno CA, Mehta Y, Higuera F, et al. Device-associated nosocomial infections in 55 intensive care units of 8 developing countries. Ann Intern Med. 2006 [cited 2016 Nov 7];145:582-591. Available from: http://www.ncbi.nlm.nih.gov/pubmed/17043340.

33. Rosenthal VD, Maki DG, Salomao R, Moreno CA, Mehta Y, Higuera F, et al. Device-associated nosocomial infections in 55 intensive care units of 8 developing countries. Ann Intern Med. 2006 [cited 2016 Aug 17];145:582591. Available from: http://www.ncbi.n/m.nih.gov/pubmed/17043340.

34. Dudeck MA, Horan TC, Peterson KD, Allen-Bridson K, Morrell G, Pollock DA, et al. National Healthcare Safety Network (NHSN) Report, data summary for 2010, device-associated module. Am. J. Infect. Control. Division of Healthcare Quality Promotion, National Center for Emerging, Zoonotic, and Infectious Diseases, Centers for Disease Control and Prevention, Public Health Service, US Department of Health and Human Services, Atlanta, GA 30329, USA. mdudeck@cdc.g; 2011;39:798-816.

35. Guanche-Garcell H, Requejo-Pino O, Rosenthal VD, Morales-Pérez C, Delgado-González O, Fernández-González D. Device-associated infection 
rates in adult intensive care units of Cuban university hospitals: International Nosocomial Infection Control Consortium (INICC) findings. Int I Infect Dis. 2011;15:e357-62. Available from: http://www.ncbi.n/m.nih.gov/pubmed/ 21450505.

36. El-Kholy A, Saied T, Gaber M, Younan MA, Haleim MM, El-Sayed H, et al. Device-associated nosocomial infection rates in intensive care units at Cairo University hospitals: first step toward initiating surveillance programs in a resource-limited country. Am J Infect Control Infection Control Unit, Clinical Pathology and Pediatric Departments, Faculty of Medicine, Cairo University, Cairo, Egypt.; 2012;40:e216-e220.

Submit your next manuscript to BioMed Central and we will help you at every step:

- We accept pre-submission inquiries

- Our selector tool helps you to find the most relevant journal

- We provide round the clock customer support

- Convenient online submission

- Thorough peer review

- Inclusion in PubMed and all major indexing services

- Maximum visibility for your research

Submit your manuscript at www.biomedcentral.com/submit 